\title{
NOVEL COMBINATION OF TRISODIUM CITRATE AND TRISODIUM PHOSPHATE IN REACTIVE DYEING OF COTTON: AN ATTEMPT TO REDUCE ENVIRONMENTAL IMPACT
}

\author{
ANKIT SHARMA and JAVED SHEIKH \\ Department of Textile and Fibre Engineering, \\ Indian Institute of Technology (IIT), Delhi, India \\ $\bowtie$ Corresponding author: J. Sheikh, jnsheikh@textile.iitd.ac.in
}

Received April 21, 2021

Reactive dyes are most widely used for dyeing cellulosic fabrics due to their excellent wet fastness properties, the brilliancy of shades and a wide gamut of colours. However, the exhaustion of reactive dye requires a large quantity of inorganic electrolyte, which results in excessive total dissolved solids (TDS) values of the resultant effluent. Such high TDS-containing effluents are challenging to treat and require advanced treatment techniques. The discharge of highTDS containing effluent into water-bodies can increase the salinity of the aquatic system, which can affect the delicate biochemistry of the aquatic life. This necessitates the exploration of alternative chemicals for reducing the TDS of the effluents in reactive dyeing.

The current study explores the alternate combination of trisodium citrate (TSC) and trisodium phosphate (TSP) as an eco-friendly replacement of inorganic salts and alkali in the dyeing of cotton by the exhaust process. The TSC-TSP combination resulted in an insignificant variation in exhaustion, fixation and fastness ratings compared to the conventional salt-soda combination. The colour values showed marginal variations in the individual cases of dyes. However, the use of the TSC-TSP combination showed a great promise in reducing the TDS of the effluent (by 66\%), which is a major concern in effluent treatment. TSC being organic, some increase in COD/BOD values was obtained; however, the effluent remained in a category of easily treatable ones.

Keywords: reactive dyeing, trisodium citrate, trisodium phosphate, TDS

\section{INTRODUCTION}

In recent years, due to the gradual advancement towards manufacturing dyed textiles considering the ecological impact, humankind is increasingly showing interest in eco-friendly dyeing of textile materials. Natural materials based on cellulosic fibres, such as cotton and linen, are the most widely used fibres for apparel production due to their hydrophilicity, wearing comfort, excellent dyeability, and biodegradability. Traditionally, reactive dyes are among the most often preferred ones for dyeing such materials, due to their brilliancy of shades, availability of a wide range of colours to achieve the desired hue, ease of application and good wash fastness properties as a result of the formation of a covalent bond between the fibre and the dye molecule. ${ }^{1}$ However, reactive dyes also have some disadvantages and the procedures used to overcome them make reactive dyeing an environmentally threatening process.

Reactive dyes show a poor to moderate affinity towards cotton because of the repulsion between the anionic dyes and the anionic surface charge generated on the cotton fibre during dyeing, which adversely affects the dye bath exhaustion on the fibre. The exhaustion is improved by the addition of electrolytes, such as sodium chloride $(\mathrm{NaCl})$ or sodium sulphate $\left(\mathrm{Na}_{2} \mathrm{SO}_{4}\right)$. Generally, dyeing of one $\mathrm{kg}$ of cotton using reactive dyes requires 80 to $160 \mathrm{~L}$ of water, $0.7-0.9 \mathrm{~kg}$ of $\mathrm{NaCl}$, and $40-70 \mathrm{~g}$ of dyestuffs. Even after the addition of the required quantity of exhausting agents, only $65-75 \%$ dye-exhaustion takes place, while the remaining $25-35 \%$ of the dyes with added common salt and alkali become part of a coloured effluent, which is discharged to an effluent treatment plant. $^{2}$ The used salt, unreacted and hydrolysed reactive dyes result in 
dye-deposit on the fabric surface. This requires several washing cycles, both with hot and cold water, to remove such dyes from the surface of the fabric, which also results in high water and energy consumption. The higher salinity causes adverse effects on the membranes used in the reverse osmosis process, which affects the ultimate economy of the effluent treatment process. The recovery of salt using the evaporation process is an expensive option. During effluent treatment, a small portion of salt is removed, while the remaining quantity is discharged into water bodies, causing detrimental effects on aquatic life.

Thus, to reduce the ecological issues caused by the exhaust method of reactive dyeing and to eliminate the requirement of salt, various approaches have been suggested, such as the modification of the dye structure and cationisation of cotton fibre before dyeing in order to improve the substantivity of the dye, ${ }^{1-24}$ the use of organic biodegradable compounds in the dyebath formulation and the modification of the dyeing machinery and processes. ${ }^{25}$ Some works dealing with the grafting of cotton with cationic polymers for salt-free reactive dyeing have been recently reported. ${ }^{26,27}$ The modification of the dye structure was found successful for bifunctional dyes; while the polyfunctional dyes achieved no commercial success because of their very high molecular weight, which causes poor dye migration, poor dye penetration inside the fibre and poor levelness. Thus, the application of such dyes was restricted to only lighter shades. ${ }^{25}$ Machinery and process modification in the industry is not a relevant technique, as it requires high costs and additional skills to standardise the operating procedure. Also, a zero liquid discharge treatment system and regular use of high salinity water cause scaling of membranes and machinery.

Even though various concepts have been explored on a laboratory scale, most of the technologies have not been tried commercially. Various cationizers available in the market are marketed as eco-friendly replacements of salt in reactive dyeing. The application of such cationizers results in various issues like the unevenness of shade, tonal variations and dullness of dyed fabrics. Apart from this, in the quest for lower effluent TDS, the organic cationizers enhance the COD/BOD of the effluent. This necessitates the development of eco-friendly reactive dyeing with the alternate salt-alkali combination. Trisodium salts, such as trisodium citrate (TSC), can offer many advantages, for example, the requirement of lower dosages, better biodegradability and lower toxicity. In the scarce reports regarding the application of TSC in the dyeing of cotton with reactive dyes available in the literature, ${ }^{28-30}$ TSC has been shown as an ideal replacement of common salt and Glauber's salt in reactive dyeing.

As trisodium citrate offers a slightly alkaline $\mathrm{pH}$, it can also lower the requirement of alkali in the fixation process. The broad objective of the work is to explore the TSC-TSP combination as an eco-friendly alternative to the common salt $(\mathrm{NaCl})$-soda ash system for achieving a lower environmental impact in reactive dyeing of cotton. In the present research work, the cotton woven fabric was dyed with vinyl sulphone-based and heterobifunctional reactive dyes by the exhaust dyeing process, and comparative studies between the conventional salt-soda system and the novel TSC-TSP systems were made. Various dyeing aspects, such as exhaustion, fixation, colour values and fastness properties, were evaluated. The effect of TSC-TSP on the physical properties of cotton fabric was also analysed. The effluents arising from both systems were analysed in terms of their eco-parameters.

\section{EXPERIMENTAL \\ Materials}

Surya processors supplied bleached cotton fabric (EPI-70, PPI-55, GSM-125, absorbency: 1 second, core $\mathrm{pH}$ 7.2, and whiteness index: 78). Reactive dyes C.I. Reactive blue 221 (heterobifunctional (ME) reactive dye) and C.I. Reactive blue 220 (vinyl sulphone (VS) based) were supplied by Ms. Colourtex and Jay Dyes and Chemicals, India. The wetting agent and the sequestering agent were supplied by Rossari Biotech Limited. All the other chemicals (acetic acid, trisodium citrate and trisodium phosphate) were of laboratory grade and purchased from Sigma Chemicals.

\section{Methods}

\section{Dyeing of cotton with reactive dye}

The cotton fabrics were dyed with two reactive dyes (ME and VS, 2\% shade), separately, as per the procedure and recipe (wetting agent: $0.5 \mathrm{~g} / \mathrm{L}$, sequestering agent: $0.5 \mathrm{~g} / \mathrm{L}$, MLR: 1:20) used on a commercial scale. Firstly, the fabric was treated with the dye and other auxiliaries in the dye pot (IR dyeing machine) at $40{ }^{\circ} \mathrm{C}$ for $5 \mathrm{~min}$. Then, the temperature was increased to $80{ }^{\circ} \mathrm{C}$ with a gradient of $1.5^{\circ} \mathrm{C} / \mathrm{min}$, and dyeing was continued for $30 \mathrm{~min}$. The dyebath was further cooled down to $60{ }^{\circ} \mathrm{C}$ (gradient: $2{ }^{\circ} \mathrm{C} / \mathrm{min}$ ), followed by the addition of alkali. The dyeing process 
was continued at $60{ }^{\circ} \mathrm{C}$ for $45 \mathrm{~min}$. After completion of dyeing, the dyeing solution was cooled to $40{ }^{\circ} \mathrm{C}$. A small sample cutting was taken from the dyed fabric, and the remaining fabric was subjected to aftertreatments, i.e. a hot wash, soaping at $95{ }^{\circ} \mathrm{C}$ for 20 min, neutralisation using acetic acid, hot wash and cold wash. Dyebath effluent samples of the various processes were collected for ecological testing. The dyed samples were dried and conditioned at $21{ }^{\circ} \mathrm{C}$ for $60 \mathrm{~min}$ at $65 \%$ relative humidity. Various concentrations of TSC and TSP used are listed in Table 1.

\section{Evaluation of exhaustion and fixation of dye}

During dyeing before soda addition, i.e. after the exhaustion cycle, colour solutions from different treatment baths were taken for assessment of the concentration of the dye remaining in the bath. The decrease in absorbance of the dyebath solution after the exhaustion cycle was utilised for evaluation of exhaustion (\%). Exhaustion (\%) was calculated using the formula:

Exhaustion $(\%)=\frac{(A-B)}{A} \times 100$

where $\mathrm{A}=$ absorbance of the solution before dyeing; $\mathrm{B}$ $=$ absorbance of the solution after exhaustion.

The loss in the colour value of the fabric after soaping was utilised for the evaluation of fixation (\%). The fabric sample was cut after the fixation cycle, and the remaining fabric was subjected to soaping at $95{ }^{\circ} \mathrm{C}$ for $20 \mathrm{~min}$, followed by neutralisation using acetic acid, a hot wash and rinsing until bleeding stops. The $\mathrm{K} / \mathrm{S}$ values of the fabric before and after soaping were measured on computer colour matching software (Gretag Macbeth Color Eye 7000A). The fixation was calculated using the formula:

Fixation $(\%)=\frac{(\mathrm{K} / \mathrm{s} \text { Before soaping }-\mathrm{K} / \mathrm{s} \text { After soaping) }}{\mathrm{K} / \mathrm{s} \text { Before soaping }} \times 100$

\section{Evaluation of dyed fabrics}

Colour value and colour fastness

The colour values of dyed fabric, i.e. depth of colour, was analysed using a computer colour matching spectrophotometer (Gretag Macbeth ColorEye 7000A). All the measurements were taken under a D65 illuminant and $10^{\circ}$ standard observer. The specular component of light was included, and the UV component was excluded $(400-700 \mathrm{~nm})$ from the spectrophotometer during measurement. The CIELAB colour space was used, and calculations were made according to CIELAB (1976) formulae. The colour strength of the dyed sample was determined by the K/S value (at $\lambda_{\max }$, i.e. $613 \mathrm{~nm}$ and $610 \mathrm{~nm}$ ), which was calculated using the Kubelka-Munk equation:

$\mathbf{K} / \mathbf{S}=\frac{(1-R)^{2}}{2 R}$

where $\mathrm{R}=$ reflectance; $\mathrm{K}$ = absorption coefficient; $\mathrm{S}=$ scattering coefficient.

The dyed fabrics were also evaluated for colour fastness to rubbing (ISO $105 \mathrm{X} 12),{ }^{31}$ colour fastness to washing (AATCC-61 1A), ${ }^{32}$ and colour fastness to light (AATCC-16 Option-3). ${ }^{32}$

\section{Mechanical properties of dyed fabrics}

The dyed fabrics were tested for mechanical properties, including crease recovery angle (AATCC$66),{ }^{32}$ bending length (ASTM-D-1388) ${ }^{33}$ and tensile strength (ASTM-D5034). ${ }^{33}$

Table 1

Trials taken for combination of TSC and TSP

\begin{tabular}{ccc}
\hline Sample name & $\begin{array}{c}\text { Exhausting agent } \\
(\mathrm{g} / \mathrm{L})\end{array}$ & $\begin{array}{c}\text { Alkali } \\
(\mathrm{g} / \mathrm{L})\end{array}$ \\
\hline \multicolumn{3}{c}{ Dye used: C.I. Reactive blue 221 } \\
\hline $\mathrm{T}_{1}$ & Common salt-60 & Soda ash-20 \\
$\mathrm{T}_{2}$ & TSC-35 & TSP-15 \\
$\mathrm{T}_{3}$ & TSC-30 & TSP-15 \\
$\mathrm{T}_{4}$ & TSC-35 & TSP-10 \\
$\mathrm{T}_{5}$ & TSC-30 & TSP-10 \\
$\mathrm{T}_{6}$ & TSC-35 & Soda ash-20 \\
\hline \multicolumn{3}{c}{ Common salt-60 } \\
$\mathrm{P}_{1}$ & TSC-35 & Soda ash-20 \\
$\mathrm{P}_{2}$ & TSC-30 & TSP-15 \\
$\mathrm{P}_{3}$ & TSC-35 & TSP-15 \\
$\mathrm{P}_{4}$ & TSC-30 & TSP-10 \\
$\mathrm{P}_{5}$ & TSC-35 & TSP-10 \\
$\mathrm{P}_{6}$ & & Soda ash-20 \\
\hline
\end{tabular}




\section{Evaluation of effluent characteristics}

The $\mathrm{pH}$ of the effluent was evaluated as per the standard IS 3025(Part-11). ${ }^{34}$ The TDS of the effluent was measured by a TDS meter (Eutech, Thermo Scientific, USA). Chemical Oxygen Demand (COD) of the effluent was evaluated using Nanocolor COD HR 1500 bottle reagents and a COD digester. The digestion period was $30 \mathrm{~min}$ at $160{ }^{\circ} \mathrm{C}$, according to the DIN ISO 15705 method. A small amount of $\mathrm{AgSO}_{4}$ and $\mathrm{HgSO}_{4}$ was added during COD analysis to precipitate the chloride ions in the solution.

Biological Oxygen Demand (BOD) of the effluent was evaluated using the VELP BOD EVO sensor. The $\mathrm{BOD}_{5}$ values were directly read in $\mathrm{mg} / \mathrm{L}$ using the respirometry method in a closed atmosphere (VELP sensor).

\section{RESULTS AND DISCUSSION Exhaustion and fixation of reactive dyes on cotton \\ The exhaustion and fixation of reactive dyes} using various combinations of salt-alkali were evaluated and presented in Table 2.

In order to match the exhaustion and fixation values of the conventional salt-soda system, the concentrations of TSC and TSP were varied. The optimum samples can be taken as $\mathrm{T}_{2}$ and $\mathrm{P}_{2}$, compared to conventional salt-soda samples $T_{1}$ and $\mathrm{P}_{1}$. As evident from the results, the bifunctional reactive dye showed marginally better exhaustion (higher by $2.58 \%$ ) in the TSCTSP system $\left(\mathrm{T}_{2}\right)$, as compared to that in the conventional salt-soda system $\left(\mathrm{T}_{1}\right)$. The fixation values were, however, too close to conclude the superiority of any system. The colour values are the combined effect of both phenomena, apart from the removal of colour during aftertreatments. In the case of the vinyl sulphone reactive dye, comparable exhaustion and fixation values were obtained in both cases. Thus, it can be concluded that the exhaustion and fixation would vary in individual cases of reactive dyes; but the values were similar in the cases of the bifunctional and vinyl sulphone dyes studied in the present work.

Table 2

Exhaustion (\%) for various combinations of salt and alkali

\begin{tabular}{lcccc}
\hline \multicolumn{4}{c}{ Dye used: C.I. Reactive blue 221 } \\
\hline Process & $\begin{array}{c}\text { Sample } \\
\text { name }\end{array}$ & $\begin{array}{c}\text { Absorbance } \\
\text { at } 613 \mathrm{~nm}\end{array}$ & $\begin{array}{c}\text { Exhaustion } \\
(\%)^{\$}\end{array}$ & $\begin{array}{c}\text { Fixation on fabric } \\
(\%)^{\$}\end{array}$ \\
\hline Blank solution & - & 0.7357 & - & - \\
Common salt-treated & $\mathrm{T}_{1}$ & 0.140 & 80.70 & 97.5 \\
& $\mathrm{~T}_{2}$ & 0.123 & 83.28 & 97.7 \\
Combination of TSC & $\mathrm{T}_{3}$ & 0.135 & 81.63 & 97.0 \\
and TSP & $\mathrm{T}_{4}$ & 0.149 & 79.74 & 98.1 \\
& $\mathrm{~T}_{5}$ & 0.169 & 77.00 & 97.4 \\
TSC-soda & $\mathrm{T}_{6}$ & 0.120 & 83.68 & 97.8 \\
\hline \multirow{2}{*}{ Process } & \multicolumn{2}{c}{ Dye used: C.I. Reactive blue 220 } & Fixation on fabric \\
& $\mathrm{Sample}_{\text {Blank solution }}$ & Absorbance & Exhaustion & $(\%)$ \\
Common salt-treated & name & at $610 \mathrm{~nm}$ & $(\%)$ & - \\
\multirow{2}{*}{ Combination of TSC } & - & 2.14 & - & 95.1 \\
and TSP & $\mathrm{P}_{1}$ & 0.236 & 88.76 & 95.6 \\
& $\mathrm{P}_{2}$ & 0.240 & 88.0 & 94.8 \\
TSC-soda & $\mathrm{P}_{3}$ & 0.252 & 87.85 & 94.9 \\
A & $\mathrm{P}_{4}$ & 0.260 & 78.30 & 96.6 \\
\hline
\end{tabular}

$\$$ Average value of three determinations

The electrostatic repulsion between the dye and the fibre is governed by a number of sulphonic acid groups or chloride groups present in the dye molecules. The higher the number of such groups present in the dye molecule, the higher the negative charge on the dye molecule when it is dissolved in water. The type of salt and the quantity required is thus dependent on the availability of these groups in the dye molecule. In this study, it was found that the dye pickup in the presence of organic salt was insignificantly different in the case of the combinations of salt and alkali. In the preliminary work, it was found that equivalent concentrations of TSC over 
common salt resulted in higher exhaustion of the dye inside the fibre. Trisodium phosphate was used as a replacement for soda ash and is a stronger alkali than soda ash. The driving force required for exhaustion and diffusion of the dye inside the fibre is generally calculated by the ionic strength of the auxiliary taken in the dyebath. Therefore, a similar ionic strength in the dyebath was selected to optimise the replacement of the inorganic salt by the organic one. When a combination of trivalent salt and trivalent alkali was used in the dyeing bath, the ionic strength of the dyebath solution increased rapidly, thus reducing the amount of the auxiliaries required for exhaustion and fixation of the dye. Trisodium citrate being a trivalent salt gives rise to more sodium ions, which can neutralise the zeta potential and is also a weak alkali that can reduce the requirement of alkali.

\section{Colour values and colour coordinates of dyed cotton}

The relative colour strengths of dyed fabrics expressed as $\mathrm{K} / \mathrm{S}$ values were measured at the specific $\lambda_{\max }(613 \mathrm{~nm}$ and $610 \mathrm{~nm}$ for two dyes) for each trial (Table 3).

The results in Table 3 indicate similar colour values for cotton dyed with C.I. Reactive blue 221 using the TSC-TSP system and for that dyed by the conventional salt-soda system. The colour difference between the cotton dyed using both systems remain in the acceptable range. No significant tonal variations were observed in the cotton fabric dyed using the TSC-TSP combination. In the case of the VS-based reactive dye, similar colour values were obtained for samples $\mathrm{P} 1$ and $\mathrm{P} 2$, resulting in a colour difference $(\Delta \mathrm{E})$ of less than 1. However, significant variations were observed in the colour values of P1, P5 and P6. The colour difference was higher than 1 in these cases. This might be attributed to the lower $\mathrm{L}^{*}$ values and lower negative values of $b^{*}$ (indicating lower blueness) for the TSC-TSP system. The concentrations of TSC and TSP were selected based on preliminary experiments; however, a detailed optimisation is required in the individual cases of each dye. Alternately, shade cards can be prepared for the alternate TSC-TSP system to explore the shade range in primary, secondary, and tertiary combinations of three primary colours generally used for dyeing textiles. The lower quantity of chemicals used in the TSC-TSP system was expected to offer advantages in the effluent load. The fixation (\%) of the bifunctional reactive dye was better than that of the vinyl sulphone-based reactive dye. The colour values and colour strengths of the dyed fabrics are the combined effect of exhaustion and fixation of the dye on fabric. As both exhaustion and fixation were found comparable for both systems, similar colour values of the dyed fabrics were expected.

Another critical concept in dyeing is the diffusion of the dye from the surface to the core of the fibre. Better diffusion prevents bleeding of the dye during soaping. Surface colour, loosely held dyes and hydrolysed reactive dyes generally come out during soaping. The comparative fixation values indicate insignificant differences in the diffusion of the dye. However, TSC is expected to act as a better exhausting agent than common salt in the reactive dyeing of cotton. TSC, after the dissociation of $\mathrm{Na}^{+}$, can lead to negatively charged COO- ions in the dyebath, which are expected to repel dye anions. This can cause better exhaustion of the dye on the fibre and better diffusion of the dye inside the core of the fibre.

Table 3

Colour values and coordinates of the TSC and TSC-TSP system

\begin{tabular}{cccccc}
\hline Sample name & $\mathrm{L}^{*}$ & $\mathrm{a}^{*}$ & $\mathrm{~b}^{*}$ & $\Delta \mathrm{E}^{*}$ & $\mathrm{~K} / \mathrm{S}$ \\
\hline $\mathrm{T}_{1}$ & 34.18 & -0.20 & -30.51 & - & 12.00 \\
$\mathrm{~T}_{2}$ & 34.30 & -0.39 & -30.70 & 0.30 & 10.62 \\
$\mathrm{~T}_{5}$ & 34.58 & -0.11 & -30.84 & 0.53 & 9.77 \\
$\mathrm{~T}_{6}$ & 34.45 & -0.53 & -30.79 & 0.52 & 10.71 \\
\hline $\mathrm{P}_{1}$ & 46.40 & -8.17 & -32.28 & - & 6.49 \\
$\mathrm{P}_{2}$ & 46.32 & -7.94 & -31.38 & 0.88 & 6.43 \\
$\mathrm{P}_{5}$ & 45.50 & -8.10 & -27.29 & 5.02 & 5.16 \\
$\mathrm{P}_{6}$ & 45.96 & -7.56 & -31.49 & 1.05 & 6.31 \\
\hline
\end{tabular}


Table 4

Fastness properties of dyed cotton

\begin{tabular}{lccccc}
\hline \multirow{2}{*}{ Treatment } & Sample & Washing & \multicolumn{2}{c}{ Rubbing fastness } & \multirow{2}{*}{$\begin{array}{c}\text { Light } \\
\text { fastness }\end{array}$} \\
\cline { 1 - 1 } Conventional salt and soda system & $\mathrm{T}_{1}$ & 4 & 4 & $3-4$ & 4 \\
& $\mathrm{P}_{1}$ & 4 & 4 & $3-4$ & 4 \\
\hline \multirow{2}{*}{ TSC-TSP combination as a } & $\mathrm{T}_{2}$ & 4 & 4 & $3-4$ & 4 \\
replacement of the conventional & $\mathrm{T}_{3}$ & 4 & 4 & $3-4$ & 4 \\
system & $\mathrm{P}_{2}$ & 4 & $3-4$ & $3-4$ & 4 \\
& $\mathrm{P}_{3}$ & 4 & 4 & 4 & 4 \\
\hline \multirow{2}{*}{ TSC and soda system } & $\mathrm{T}_{6}$ & 4 & 4 & $3-4$ & 4 \\
& $\mathrm{P}_{6}$ & 4 & 4 & 4 & 4 \\
\hline
\end{tabular}

Table 5

Crease recovery angle, bending length \& tensile strength of treated fabrics

\begin{tabular}{lcccc}
\hline Treatment & $\begin{array}{c}\text { Sample } \\
\text { name }\end{array}$ & $\begin{array}{c}\text { Bending length } \\
(\mathrm{cm})\end{array}$ & $\begin{array}{c}\text { Crease recovery } \\
\text { angle }\left({ }^{\circ}\right)^{\$}\end{array}$ & $\begin{array}{c}\text { Tensile strength in weft } \\
(\mathrm{N}){ }^{\$}\end{array}$ \\
\hline Control sample & & 4.2 & 159 & 321 \\
\hline Conventional salt and soda & $\mathrm{T}_{1}$ & 4.1 & 161 & 280 \\
system & $\mathrm{P}_{1}$ & 4.3 & 164 & 294 \\
\hline \multirow{2}{*}{ TSC-TSP system } & $\mathrm{T}_{2}$ & 4.3 & 163 & 274 \\
& $\mathrm{P}_{2}$ & 4.3 & 163 & 277 \\
\multirow{2}{*}{ TSC-soda system } & $\mathrm{T}_{6}$ & 4.3 & 165 & 283 \\
& $\mathrm{P}_{6}$ & 4.4 & 165 & 286 \\
\hline
\end{tabular}

$\$$ Average value of three determinations

\section{Fastness properties of dyed cotton}

The various dyed samples were tested for washing fastness, rubbing fastness and light fastness, and the results are tabulated in Table 4.

Comparative fastness ratings were obtained in both cases. In general, the fastness properties of dyed fabrics are dependent on the dye-fibre interactions. These are also governed by the exhaustion, diffusion and fixation processes - the dye molecules reacting with the fibre result in lower bleeding of the dye. The major factors that can lower the fastness properties include incomplete fixation, poor diffusion and the hydrolysis of dye during the dyeing process. As comparative ratings were obtained, such phenomena were expected to occur to a similar extent. This also validates the comparative dyefibre interactions in both cases.

\section{Mechanical properties of dyed fabrics}

The various dyed samples were tested for mechanical properties, including crease recovery angle, bending length and tensile strength. The results are tabulated in Table 5.

The tensile strength of the fabric got reduced after dyeing. This might be attributed to the dyeing of cotton with reactive dyes, where the reaction between the reactive dye and the hydroxyl groups of cotton results in lowering of the availability of hydroxyl groups for hydrogen bonding. The reduction in hydrogen bonding between the adjacent cellulosic chains reduces the load-bearing capacity and the flexibility of fabric during tensile load application. The fixation carried out in the presence of alkali and air can also result in depolymerisation of the cellulosic chain and the formation of oxycellulose. No clear conclusions can be drawn from the data obtained for tensile strength. Bending length and CRA showed no significant differences between the studied systems.

\section{Ecological analysis of effluents}

The effluent samples arising from the dyebath were tested in terms of their ecological parameters. The data obtained are detailed below.

\section{$p H$, total dissolved solids and conductivity of effluent samples}

Total dissolved solids are the sum of all organic and inorganic substances in a liquid present in molecular or ionised form. The solids must be small enough to pass through a sieve having a size of 2-3 micrometres during filtration. Ions in the dissolved solids cause the water to conduct electrical current, which is measured by 
the TDS analyser and shown in ppm or $\mathrm{mg} / \mathrm{L}$. Sodium chloride is a strong salt with a very high dissociation constant, which gives higher ionic mobility of the ions and causes an increase in the conductivity of water. After dissociation, they always remain in ion form, thus increasing the TDS of water. The increase in conductivity of the solution increased the TDS of the solution. From the results obtained, we can conclude that the TDS of the effluent drained from the dyeing bath was significantly reduced by the replacement of common salt with trisodium citrate.

Trisodium citrate is a non-toxic salt with low reactivity. It is fully biodegradable and can be completely disposed of, along with regular waste or sewage. The $\mathrm{pH}$ of trisodium citrate ranges between 7.5-9, while the $\mathrm{pKa}$ for three sodium ions is $3.138,4.76$ and 6.40 , respectively. Trisodium citrate is a weak salt, formed by the combination of citric acid and sodium hydroxide or sodium carbonate. So, it dissociates less than sodium chloride, and one molecule on dissociation gives three $\mathrm{Na}^{+}$ions. As the dissociated ions remain in equilibrium, they combine to reduce the conductivity of water, thereby reducing the TDS.

Also, the concentration of trisodium citrate in the effluent is almost half the total concentration of inorganic salt. As the conductivity of the solution increases, the TDS of the solution also increases. From the results of this study, it can be concluded that the TDS of the effluent drained from the dyeing bath was significantly reduced by the replacement of salt using TSC. The TDS of the effluent significantly reduced from 39800 ppm to $11600 \mathrm{ppm}$ using trisodium citrate and trisodium phosphate to replace the conventional salt-soda system, without affecting the colour strength of the dyed sample. The combination of TSC-TSP can offer an ecological advantage as these compounds are biodegradable and easily separable. The effluent data are the result of analysis of the actual dyeing bath sample (raw sample), which is approximately diluted several times during several cold washes, a hot wash and soaping before going to an effluent treatment plant.

\section{Chemical oxygen demand (BOD) and biological} oxygen demand (COD) of effluent samples

The BOD/COD results for different samples and their biodegradability index are tabulated in Table 7.

The ratio of $\mathrm{BOD}_{5} / \mathrm{COD}$ is usually utilised to express the biodegradability of wastewater, also known as the biodegradability index. The COD of the effluent increased when we used an organic substitute for inorganic salt, which indicates the biodegradability of the organic matter in the effluent. The COD and BOD of the organic compound-containing effluent are generally higher than those of the inorganic salt and alkalitreated samples.

Table 6

Analysis of $\mathrm{pH}$, conductivity and TDS of effluent

\begin{tabular}{lccc}
\hline Sample name & $\mathrm{pH}$ & $\begin{array}{c}\text { Conductivity } \\
(\mu \mathrm{s} / \mathrm{ms})\end{array}$ & $\begin{array}{c}\text { Total dissolved solids (TDS) } \\
(\mathrm{ppm} / \mathrm{ppt})\end{array}$ \\
\hline Tap water & 7.23 & $325 \mu \mathrm{s}$ & $167 \mathrm{ppm}$ \\
10 g/L common salt & 7.2 & $17 \mathrm{~ms}$ & $8470 \mathrm{ppm}$ \\
10 g/L soda ash & 10.36 & $12.1 \mathrm{~ms}$ & $6080 \mathrm{ppm}$ \\
10 g/L trisodium citrate & 8.3 & $7.2 \mathrm{~ms}$ & $3610 \mathrm{ppm}$ \\
$\mathrm{T}_{1}$ (Salt-60 g/L, Soda-20 g/L) effluent drain & 10.59 & $79 \mathrm{~ms}$ & $39.8 \mathrm{ppt}$ \\
$\mathrm{T}_{6}$ (TSC-35 g/L, Soda-20 g/L) effluent drain & 10.73 & $28 \mathrm{~ms}$ & $14.1 \mathrm{ppt}$ \\
$\mathrm{T}_{2}$ (TSC-35 g/L, TSP-15 g/L) effluent drain & 10.81 & $23 \mathrm{~ms}$ & $11.6 \mathrm{ppt}$ \\
\hline
\end{tabular}

$\mu \mathrm{s}$ - microsiemens; $\mathrm{ms}$ - millisiemens; ppt - parts per thousand; ppm - parts per million

Table 7

COD and BOD of effluent samples

\begin{tabular}{lccc}
\hline Sample name & COD $(\mathrm{mg} / \mathrm{L})^{\$}$ & BOD $_{5}(\mathrm{mg} / \mathrm{L})^{\$}$ & BOD $_{5} /$ COD ratio \\
\hline Bifunctional dye (2\% shade solution) & 1880 & 760 & 0.40 \\
$\mathrm{~T}_{1}$ (Salt-60 g/L, Soda-20 g/L) effluent drain & 5340 & 2410 & 0.45 \\
$\mathrm{~T}_{6}$ (TSC-35 g/L, Soda-20 g/L) effluent drain & 8970 & 3850 & 0.43 \\
$\mathrm{~T}_{2}$ (TSC-35 g/L, TSP-15 g/L) effluent drain & 8380 & 3270 & 0.39 \\
\hline
\end{tabular}

$\$$ Average value of three determinations 
In general, a $\mathrm{BOD} / \mathrm{COD}$ ratio greater than 0.7 represents easily biodegradable wastewater, and can be easily treated by biological treatment. If the BOD/COD ratio lies between 0.35 and 0.7 , feeding with microorganisms is necessary for biological treatment, as the processing activity is slow. In this case, the acclimatisation of microbes helps in the degradation process of organic substances present in water. However, if the $\mathrm{BOD} / \mathrm{COD}$ ratio is less than 0.3 , biodegradation will not happen, and it is not possible to treat the effluent biologically. This is explained by the fact that the wastewater produced from such sources inhibits the metabolic activity of bacterial seed and microbes because of the toxic nature of the effluent. As the biodegradability index $\left(\mathrm{BOD}_{5} / \mathrm{COD}\right)$ for all these effluents is higher than 0.4 , bacterial seeding is necessary to treat them biologically, as the process is slow. COD reduction and colour removal can occur in biological treatment, and these organic compounds can act as food for microorganisms during the biological treatment process. Thus, these are biodegradable and can be removed from the effluent water as sludge.

\section{CONCLUSION}

Trisodium citrate, an organic biodegradable substance, can be used for replacing common salt in dyeing cotton textiles. Due to the low consumption of trisodium citrate, the total dissolved solids can be reduced by three times, compared to the conventional process of dyeing. The combination of trisodium citrate and trisodium phosphate to replace the necessary salt and alkali offers the added advantage of providing equivalent or better colour yield and fastness properties. The requirement of lower dosage can help in both economic and ecological aspects. The various alternatives for the salt in reactive dyeing, as studied in the present research, act in a similar way, and the observed trends were comparable in the case of both vinyl sulphone-based and bifunctional reactive dyes.

\section{REFERENCES}

1 N. Arivithamani and V. R. G. Dev, Clean Technol. Environ. Policy, 19, $2317 \quad$ (2017), https://doi.org/10.1007/s10098-017-1425-y

2 L. Fang, X. Zhang, J. Ma, D. Sun, B. Zhang et al., RSC Adv., 5, $45654 \quad$ (2015), https://doi.org/10.1039/C5RA05887B

3 M. R. Bhuiyan, A. Shaid and M. A. Khan, Chem. Mater. Eng., 2, $96 \quad$ (2014), https://doi.org/10.13189/cme.2014.020402

4 W. Ma, M. Meng, S. Yan and S. Zhang, Chin. J.

Chem. Eng., 24, 175 (2016), https://doi.org/10.1016/j.cjche.2015.07.008

5 N. Arivithamani and V. R. G. Dev, J. Clean. Prod., 183 , 579

(2018),

https://doi.org/10.1016/j.jclepro.2018.02.175

6 S. Houshyar and S. H. Amirshahi, Iran. Polym. J., 11, $295 \quad$ (2002), https://www.sid.ir/en/journal/ViewPaper.aspx?ID=338 87

7 T. Öktem, Color. Technol., 119, 241 (2003), https://doi.org/10.1111/j.1478-4408.2003.tb00179.x

8 N. Arivithamani and V. R. G. Dev, J. Clean. Prod., 149, 1188

(2017),

https://doi.org/10.1016/j.jclepro.2017.02.162

9 L. Fang, X. Zhang, J. Ma, D. Sun, B. Zhang et al., $\begin{array}{llll}R S C & A d v ., & 5 & \end{array}$ https://doi.org/10.1039/C5RA05887B

10 T. S. De Vries, D. R. Davies, M. C. Miller and W. A. Cynecki, Ind. Eng. Chem. Res., 53, 9686 (2014), https://doi.org/10.1021/ie500836n

11 K. Singha, S. Maity and M. Singha, Int. J. Text. $\begin{array}{llll}\text { Sci., } & \mathbf{1}, & 69 & \text { (2012), }\end{array}$ https://doi.org/10.5923/j.textile.20120106.03

12 D. P. Chattopadhyay, R. B. Chavan and J. K. Sharma, Int. J. Cloth. Sci. Technol., 19, 99 (2007), https://doi.org/10.1108/09556220710725702

13 N. Ristić and I. Ristić, J. Eng. Fibers Fabr., 7, 113 (2012),

https://journals.sagepub.com/doi/pdf/10.1177/1558925 01200700408

14 A. Nallathambi and G. D. V. Rengaswami, Carbohyd. Polym., 174, $137 \quad$ (2017), https://doi.org/10.1016/j.carbpol.2017.06.045

15 L. M. Wangatia and G. B. Tseghai, J. Text. Inst., 107, 1375 (2016), https://doi.org/10.1080/00405000.2015.1114350

16 S. M. Burkinshaw, M. Mignanelli, P. E. Froehling and M. J. Bide, Dyes Pigm., 47, 259 (2000), https://doi.org/10.1016/S0143-7208(00)00053-X

17 A. K. Samanta, T. R. Kar, A. Mukhopadhyay, D. Shome and A. Konar, Text. Res. J., 86, 2179 (2016), https://doi.org/10.1177/0040517515621135

18 S. M. Burkinshaw, X. P. Lei and D. M. Lewis, $J$. Soc. Dyers Colour., 105, $391 \quad$ (1989), https://doi.org/10.1111/j.1478-4408.1989.tb01189.x

19 D. Hinks, S. M. Burkinshaw, D. M. Lewis and A. H. M. Renfrew, AATCC Rev., 1, 43 (2001), https://aatcc.org/magazine/

20 S. Zhang, W. Ma, B. Ju, N. Dang, M. Zhang et al., Color. Technol., 121, 183 (2005), https://doi.org/10.1111/j.1478-4408.2005.tb00270.x

${ }^{21}$ M. Zhang, B. Z. Ju, S. F. Zhang, W. Ma and J. Z. Yang, Carbohyd. Polym., 69, 123 (2007), https://doi.org/10.1016/j.carbpol.2006.09.011

22 B. T. Teklemedhin, J. Text. Sci. Eng., 8, 365 (2018), https://doi.org/10.4172/2165-8064.1000365

23 W. Ma, S. Yan, M. Meng and S. Zhang, J. Appl. 
Polym. Sci., 131,
https://doi.org/10.1002/app.40522

${ }^{24}$ T. Niu, X. Wang, C. Wu, D. Sun, X. Zhang et al., ACS Omega, 5, $15409 \quad$ (2020), https://doi.org/10.1021/acsomega.0c01530

25 A. Khatri, M. H. Peerzada, M. Mohsin and M. White, J. Clean. Prod., 87, 50 (2015), https://doi.org/10.1016/j.jclepro.2014.09.017

26 W. Dong, M. Zhou, Y. Li, S. Zhai, K. Jin et al., Colloids Surf., A, 594, 124573 (2020), https://doi.org/10.1016/j.colsurfa.2020.124573

27 W. Ma, S. Du, S. Yan, X. Yu, Z. Zhang et al., Polymers, 12, 462 (2020), https://doi.org/10.3390/polym 12020462

28 H. Gurumallesh Prabu and M. Sundrarajan, Color. Technol., 118, 131 (2002), https://doi.org/10.1111/j.1478-4408.2002.tb00370.x
29 S. A. Abo Farha, A. M. Gamal, H. B. Sallam, G. E. A. Mahmoud and L. F. M. Ismail, J. Am. Sci., 6, 109 (2010), https://doi.org/10.7537/marsjas061010.15

30 K. Murugesh Babu and M. Selvadass, Univers. J. Environ. Res. Technol., 2, 421 (2012), https://www.environmentaljournal.org/2-5/ujert-2-5-

7.pdf

31 ISO Technical Manual, Geneva, Switzerland, 2006

32 AATCC Technical Manual, American Association of Textile Chemists Colorists, Research Triangle Park, USA, 2007

33 ASTM Standards Manual, ASTM International, West Conshohocken, PA 19428-2959, USA

34 IS 3025 Method of Sampling and Test (Physical and Chemical) for Water and Wastewater, Part 11: $\mathrm{pH}$ Value (first revision), ICS 13.060.50 (1983, reaffirmed 2002) 